\title{
Behavioral Regulation Sport Questionnaire: Gender and Sport Invariance in Portuguese Athletes
}

Perceptual and Motor Skills

$0(0) 1-19$

(C) The Author(s) 2019

Article reuse guidelines: sagepub.com/journals-permissions DOI: $10.1177 / 0031512519825700$ journals.sagepub.com/home/pms

\section{Diogo Monteiro ${ }^{1,2}$ (D), Diogo S. Teixeira ${ }^{3}$,} Anabela Vitorino', João Moutão ${ }^{1,2}$, Filipe Rodrigues ${ }^{4}$, Sérgio Machado ${ }^{5,6,7}$, and Luís Cid ${ }^{1,2}$

Diogo S. Teixeira ORCID:https://orcid.org/0000-0003-4587-5903; Anabela Vitorino ORCID: https://orcid.org/0000-0003-4402-1973; João Moutão ORCID: https://orcid.org/0000-0003-0457-0070;

Filipe Rodrigues ORCID: https://orcid.org/0000-0003-1327-8872; Sérgio Machado ORCID: https://orcid.org/0000-0001-8946-8467

\begin{abstract}
This study aimed to analyze measurement invariance of the Behavioral Regulation Sports Questionnaire (BRSQ) across the-gender and four different sports. In addition, we examined nomological validity via basic psychological needs satisfaction. Participants totaled I,8I 2 Portuguese athletes (I,220 males and 592 females; aged I5-59 years, Mage $=17.72, S D=5.5 \mathrm{I})$ from football $(n=596)$, basketball $(n=273)$, swimming $(n=800)$, and parasport $(n=143)$. The BRSQ measurement model was invariant across the-gender and these four sports. The scale confirmed nomological validity in that satisfaction of the basic psychological needs positively predicted autonomous forms of motivation and negatively predicted more controlled
\end{abstract}

\footnotetext{
'Sport Science School of Rio Maior, ESDRM-IPSantarém, Rio Maior, Portugal

${ }^{2}$ Research Center in Sports Sciences, Health Sciences and Human Development (CIDESD), Vila Real, Portugal

${ }^{3}$ Faculty of Physical Education and Sport, Universidade Lusófona de Humanidades e Tecnologias, Lisbon, Portugal

${ }^{4}$ Department of Sport Sciences, University of Beira Interior, Covilhã, Portugal

${ }^{5}$ Laboratory of Physical Activity Neuroscience, Physical Activity Sciences Post-Graduate Program, Salgado de Oliveira University, Niterói, Brazil

${ }^{6}$ Laboratory of Panic and Respiration, Institute of Psychiatry of Federal University of Rio de Janeiro, Brazil

${ }^{7}$ Intercontinental Neuroscience Research Group, Rio de Janeiro, Brazil [AQ1]
}

\section{Corresponding Author:}

Diogo Monteiro, Instituto Politecnico de Santarem, Escola Superior de Desporto de Rio Maior, Av.

Dr. Mário Soares, Rio Maior, 2040-4I3 Rio Maior, Portugal.

Email: diogomonteiro@esdrm.ipsantarem.pt 
motivation and amotivation as suggested by self-determination theory. In light of this evidence for BRSQ construct validity, composite reliability, nomological validity, and invariance across the-gender and four different sports, this scale is a useful tool for the-coaches of the aforementioned sports in their efforts to evaluate their athletes' motivation. [AQ2]

\section{Keywords}

motivation, self-determination theory, multigroup analysis, basic psychological needs, sport

\section{Introduction}

More than 30 theories have addressed motivation in the sport context, but selfdetermination theory (SDT; Deci \& Ryan, 2000) has been one of the most widely used theoretical models for understanding cognitive, emotional, and behavioral outcomes in athletes. SDT is a macro theory about human motivation, explaining the components of intrinsic and extrinsic motivation as well as the factors that improve or weaken motivational regulation (Deci \& Ryan, 2000). According to Deci and Ryan (2008), the social environment does not directly determine the way people regulate their motivation. Instead, these authors suggest that the main factor impacting motivation is the satisfaction of three basic psychological needs (BPNs): autonomy, competence, and relatedness. Autonomy refers to the need to feel independent and autonomous in self-selected activities. Competence is related to the need to interact effectively in specific contexts. Relatedness is the need to establish interpersonal links and interact with others (Deci \& Ryan, 2008). Deci and Ryan (2008) argue that BPNs are innate and universal to all human beings, regardless of their ethnicity, gender, age, race, or cultural background, and that satisfaction of BPNs is directly linked to an individual's motivational regulation. This evidence has been empirically demonstrated by B. Chen et al. (2015) in a cross-cultural study (i.e., Belgium, China, United States, and Peru).

Motivational regulations are spread across a continuum varying from the absence of motivation or lack of intention to act (i.e., amotivation) through controlled forms (external and introjected regulation) of motivation, ending with autonomous forms (identified and integrated regulations and intrinsic motivation) (Deci \& Ryan, 2000). According to Deci and Ryan (2008), distinguishing between controlled and autonomous motivation is the main characteristic of SDT as further modified by the-Organismic Integration Theory. Organismic Integration Theory describes the process by which external regulations are internalized, leading to more self-determined behaviors. It also explains how the-different regulations impact a person's cognitive, behavioral, and affective conduct (Howard, Gagné, \& Bureau, 2017). 
Over the last few years, researchers have developed and validated SDT-based measurements that assess how people regulate their behavior in the sport context (Clancy, Herring, \& Campbell, 2017). Two of the most well-known instruments for this purpose are the Sport Motivation Scale (SMS; Pelletier et al., 1995; Pelletier, Rocchi, Vallerand, Deci, \& Ryan, 2013) and the Behavioral Regulation Sport Questionnaire (BRSQ; Lonsdale, Hodge, \& Rose, 2008). According to Lonsdale et al. (2008), the BRSQ was developed mainly because of the psychometric problems in the SMS, though these authors highlighted the need for further improving both scales. In addition, the original version of SMS (Pelletier et al., 1995) did not measure integrated regulation, giving this tool a shortcoming in predicting behavioral regulations. Recently, the BRSQ has been translated into various languages and validated in countries, such as the Netherlands (Assor, Vansteenkinste, \& Kaplan, 2009), China (Chan, Hagger, \& Spray, 2011), Greece (Tsitskari, Vernadakis, Foridou, \& Bebetsos, 2015), Spain (Moreno-Murcia, Marzo, Martínez-Galindo, \& Marín, 2011; Villadrich, Torregrossa, \& Cruz, 2011), and Portugal (Monteiro, Moutão, \& Cid, 2018). [AQ3] Despite its multinational validation and good psychometric properties, the BRSQ's measurement invariance has not been investigated, except in the Swedish version (Stenling, Ivarsson, Lindwall, \& Gucciardi, 2018) for which there is support for longitudinal invariance. Even in the Swedish instance, researchers noted the instrument's limitations and stressed the need to replicate this invariance in other settings and for other parameters (e.g., other sports, levels of competition, and cultural backgrounds). Monteiro et al. (2018) called for more studies (e.g., to test invariance across the-gender, age groups, and different sports).

\section{The Present Study}

In this study, we aimed to analyze BRSQ invariance across the-gender and four different sports while also examining the nomological validity between BPNs' satisfaction and different forms of motivation. SDT constructs are assumed to be universal influences on human motivation (Deci \& Ryan, 2000, 2008), as also highlighted in other studies (e.g., Villadrich et al., 2013), since constructs underlying behavioral regulations have shown invariance across the-gender (Lonsdale et al., 2008), competitive level (Hancox, Quested, Villadrich, \& Duda, 2015), and cultural background (Villadrich et al., 2013). Consequently, and according to Stenling et al. (2018) and Monteiro et al. (2018), we hypothesised that the BRSQ would be invariant across the-gender and across different sports.

In line with SDT (Deci \& Ryan, 2000; Ryan \& Deci, 2017) and others who have recognized this theory (e.g., Álvarez, Balaguer, Castillo, \& Duda, 2012; Jõseaar, Hein, \& Hagger, 2012; Sarrazin, Vallerand, Guillet, Pelletier, \& Cury, 2002), the individual's satisfaction of BPNs should be associated with an increase in more autonomous forms of motivation. We sought to demonstrate this empirically by showing within the BRSQ a positive correlation of BPNs 
with autonomous forms of motivation and a negative correlation of BPNs with controlled motivation and amotivation.

\section{Method}

\section{Participants}

Our participants were 1,812 Portuguese athletes (1,220 males and 592 females), practicing different sports and aged 15 - to 59 years $(M=17.72 ; S D=5.51)$. All participants competed in national or international championships. Their sport experience varied from 1 to-29 years $(M=8.22 ; S D=3.92)$, weekly training ranged from 1 to-12 sessions $(M=5.13 ; S D=2.22)$, and volume training varied from 60,to-150 minutes $(M=106.14 ; S D=24.21)$. To test the-measurement invariance, the sample was split into four groups, according to the type of sport practiced: football $(n=596)$, basketball $(n=800)$, swimming $(n=273)$, and parasport $(n=143)$. Characteristics of each group are presented in Table 1. The participants in the parasport group were engaged in several sports (swimming, athletics, basketball, boccia, and judo) and had one or more disabilities (e.g., cerebral paralysis, deafness, and motor or visual disabilities).

\section{Instruments}

Behavioral Regulation Sport Questionnaire. In this study, we used the Portuguese version of the BRSQ (Monteiro et al., 2018), a 24-item questionnaire that has been found to be a valid measure of amotivation and extrinsic, introjected, identified, integrated, and intrinsic forms of motivation (e.g., Monteiro et al., 2018). In this questionnaire, respondents are required to answer each item on 7-point Likerttype scale, with categorizations varying from 1 (not at all true) to 7 (very true).

Basic Psychological Needs Exercise Scale. To measure BPNs related to exercise, we used the Basic Psychological Needs Exercise Scale, adapted and validated to sport context by Monteiro et al. (2016). The 12 items of this scale are grouped into three factors (four items per factor) that represent the three BPNs. Responses are given on a 5-point Likert-type scale ranging from 1 (totally disagree) to 5 (totally agree). We calculated composite reliability and considered it to be appropriate to reflect item consistency in BPN groupings (autonomy $=.70$; competence $=.77$, and relatedness $=.85$ ).

\section{Procedures: Data Collection}

For this study, a convenience sample from different sports-was used (football, basketball, swimming, and parasport), as we did not have the necessary means to collect data in other or more specific sport. 


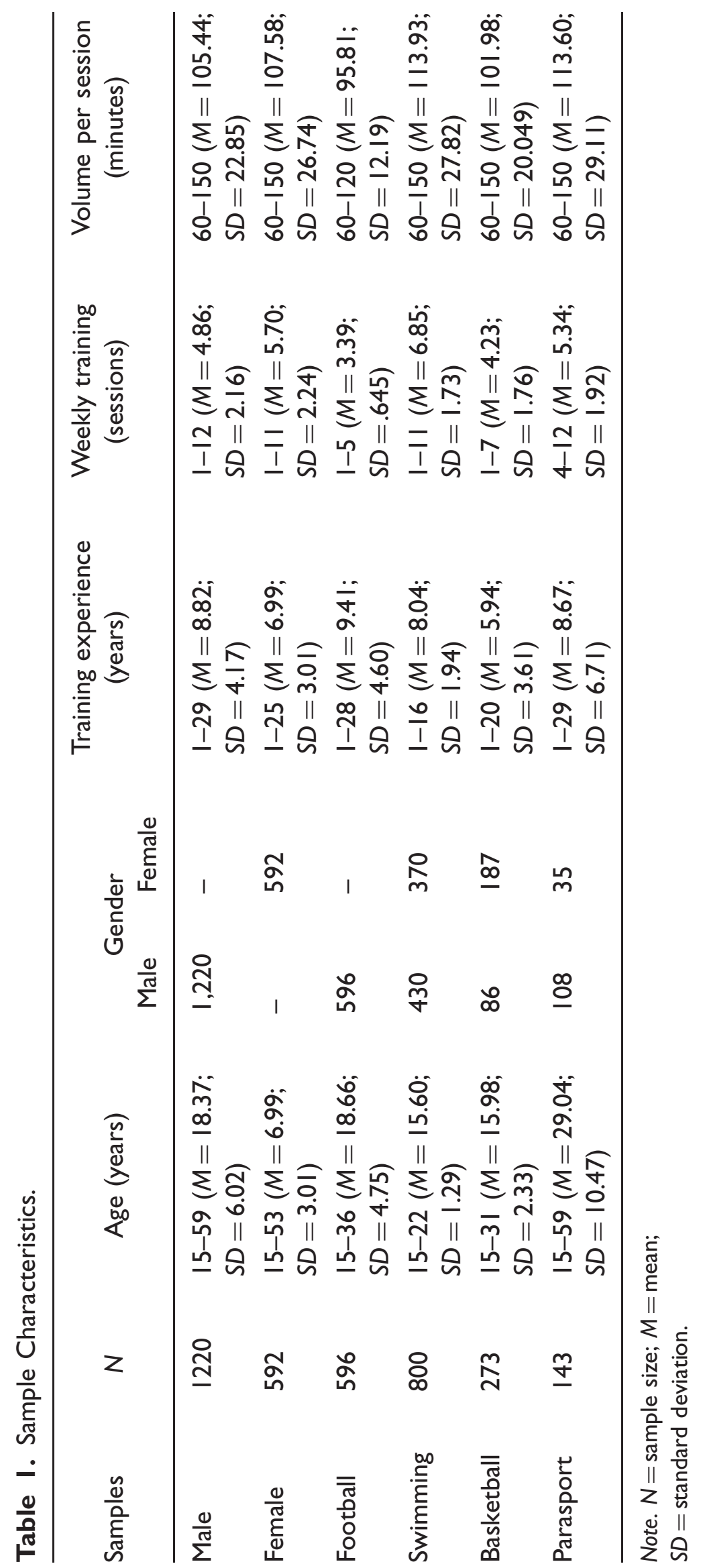


First, we contacted sports club managers and informed them about the study's objectives. Following their approval to proceed with data collection, we next contacted coaches to arrange a suitable time for data collection. Third, after procuring informed written consent from all the participants, athletes were asked to complete the questionnaires before their training session. For underaged athletes, we obtained informed consent from their parents. All participants were guaranteed personal confidentiality. It should also be noted that parasport participants completed the questionnaire as autonomously as possible, though parasport participants who were unable to complete the questionnaire on their own received assistance from their coach or from a family member. In such situations, we reinforced the imperative of participant confidentiality and bias prevention. Average time taken to complete the questionnaires was 20 minutes. We obtained ethical approval from the committee of the Research Center in Sports Sciences, Health Sciences and Human Development (CIDESD) under the reference UID/DTP/04045/2013.

\section{Data Analysis}

We calculated descriptive statistics (means and standard deviations) for each construct. We performed a maximum likelihood method of structural equation modeling using AMOS 23.0. First, we conducted confirmatory factor analysis to test the psychometric properties for each measurement model. Second, we conducted structural equation modeling in order to demonstrate the-nomological validity among BPNs and different types of motivation. For both analyses, we followed the recommendations of several authors (Byrne, 2010; Hair, Black, Babin, \& Anderson, 2014; Marsh, Hau, \& Wen, 2004). We used the following goodness-of-fit indexes: standardized root mean square residual (SRMR), Comparative Fit Index (CFI), Tucker-Lewis Index, root mean square error of approximation (RMSEA), and the respective confidence interval (90\% CI). For these indexes, the following cut-off values were adopted: CFI and Tucker-Lewis Index $\geq .90$ and SRMR and RMSEA $\leq .08$ (Byrne, 2010; Hair et al., 2014; Marsh et al., 2004).

Convergent validity was examined through average variance extracted (AVE) calculation, considering adjusted values of $\mathrm{AVE} \geq .50$. Discriminant validity was verified when the AVE of each construct exceeded the squared correlations between that construct and any other construct (Hair et al., 2014). Internal consistency was calculated via composite reliability, adopting .70 as cut-off value (Hair et al., 2014). Nomological validity was analyzed through standard errors of measurement between BPNs and the different motivational regulations. To assess significance, 90\% CI values were scrutinized such that values should not encompass zero (Hair et al., 2014; Liu, Li, \& Zhu, 2012).

To demonstrate measurement invariance of the BRSQ across different groups, we adopted the recommendations of Byrne (2010), F. Chen (2007), 
and Cheung and Rensvold (2002) that (a) the measurement model should present a good fit to the data in each sample under analysis and (b) the following invariance types should be analyzed: (i) configural invariance (baseline model, which factor loadings, intercepts, and residuals are freely estimated), (ii) metric invariance (all factor loading are equal), (iii) scalar invariance (all factor loading and item intercepts are equal), and (iv) residual invariance (all factor loadinge item intercepts and residual are equal). Moreover, invariances were understood from a practical standpoint ( $\triangle \mathrm{CFI}, \triangle \mathrm{RMSEA}$, and $\triangle \mathrm{SRMR}$ ). In this study, invariance was verified as follows: (a) $\Delta \mathrm{CFI} \leq .01$, (b) $\triangle \mathrm{RMSEA} \leq .015$, and (c) $\triangle \mathrm{SRMR} \leq .03$ for factor loading invariance tests and (a) $\triangle \mathrm{CFI} \leq .01$, (b) $\triangle \mathrm{RMSEA} \leq .015$, and (c) $\triangle \mathrm{SRMR} \leq .01$ for intercept invariance tests.

\section{Results}

\section{Preliminary Analysis}

Data analysis demonstrated 12 cases of missing values (total absence of response in one of the questionnaires) and 14 univariate $(z>3.00)$ and multivariate outliers (Mahalanobis distance $=p_{1}<.001 ; p_{2}<.001$ ) were removed from the data for further analysis, as suggested by Byrne (2010). Item-level descriptive statistics showed no deviations from univariate normality in all samples (all kurtosis and skewness values varied from 7 to +7 and 2 to +2 , respectively). However, Mardia's coefficient for multivariate kurtosis showed violation of multivariate distribution in all samples (values are $>5.0$ ). Therefore, a Bollen-Stine bootstrap with 2,000 samples was performed (Nevitt \& Hancock, 2001). Finally, the association observed between BPNs of autonomy and integrated regulation was greater than .90 (Hair et al., 2014), indicative of a collinearity issue. Therefore, we calculated the variance inflation factor and obtained a value of 1 . As 10 is the cut-off value suggested by some authors (e.g., Hair et al., 2014), no collinearity issues were found.

\section{Descriptive Statistics, Internal Consistency, and Convergent and Discriminant Validity}

As shown in Table 2, autonomous forms of motivation have higher mean scores than controlled forms of motivation and amotivation. Moreover, there is evidence that all factors have adequate internal consistency values (all $>.70$ ). All the factors presented values of convergent validity, except for identified regulation. Problems were found regarding discriminant validity, more precisely between external and introjected regulation, and between identified and integrated regulations. These problems are due to the fact that the square of the correlations between these factors was higher than the AVE value of both factors (Fornell \& Larcker, 1981; Hair et al., 2014). The remaining factors did not present any discriminant validity problems. 
Table 2. Mean, Standard Deviation, Composite Reliability and Convergent and Discriminant Validity for General Sample.

\begin{tabular}{lcccccccccc}
\hline Factors & M & SD & CR & AVE & AM & EX & IJ & ID & IG & IM \\
\hline AM & 2.44 & 1.39 & .88 & .65 & I & - & - & - & - & - \\
EX & 1.76 & 1.29 & .91 & .73 & .58 & I & - & - & - & - \\
IJ & 2.09 & 1.42 & .86 & .61 & .42 & .71 & I & - & - & - \\
ID & 4.21 & .80 & .71 & .38 & .08 & .09 & .02 & I & - & - \\
IG & 4.95 & .92 & .80 & .51 & .16 & .20 & .07 & .64 & - & - \\
IM & 5.39 & 1.07 & .85 & .60 & .14 & .27 & .34 & .29 & .50 & I \\
\hline
\end{tabular}

Note. $M=$ mean; $S D=$ standard deviation; $C R=$ composite reliability; $A V E=$ average variance extracted; $A M=$ amotivation; $E X=$ external regulation; $\mathrm{I}=$ introjected regulation; $\mathrm{ID}=$ identified regulation; IG = integrated regulation; $\mathrm{IM}=$ intrinsic motivation.

Table 3. Goodness-of-Fit Indexes of the Portuguese Version of BRSQ in All Samples Under Analysis and Structural Models. [AQ10].

\begin{tabular}{lccccccccc}
\hline CFA/SEM models & $\chi^{2}$ & $d f$ & $\chi^{2} / d f$ & $B-S p$ & SRMR & TLI & CFI & RMSEA & RMSEA 90\% \\
\hline General model & $2,735.179$ & 237 & $\mathrm{II} .54$ & $<.001$ & .057 & .900 & .911 & .077 & $.074-.080$ \\
Male model & $\mathrm{I}, 687.764$ & 237 & 7.12 & $<.001$ & .059 & .901 & .917 & .072 & $.069-.075$ \\
Female model & $\mathrm{I}, 201.063$ & 237 & 5.06 & $<.001$ & .055 & .898 & .905 & .080 & $.080-.089$ \\
Football model & 816.407 & 237 & 3.44 & $<.001$ & .063 & .900 & .912 & .065 & $.061-.070$ \\
Swimming model & $\mathrm{I}, 884.376$ & 237 & 7.95 & $<.001$ & .063 & .902 & .916 & .079 & $.067-.092$ \\
Basketball model & 703.936 & 237 & 2.97 & $<.001$ & .059 & .900 & .917 & .080 & $.072-.095$ \\
Parasport model & 589.674 & 237 & 2.48 & $<.001$ & .062 & .901 & .912 & .080 & $.077-.080$ \\
SEM model & $3,842.860$ & 576 & 6.67 & $<.001$ & .080 & .900 & .922 & .080 & $.077-.086$ \\
\hline
\end{tabular}

Note. $\chi^{2}=$ chi-squared; $d f=$ degrees of freedom; $\chi^{2} / d f=$ normalized chi-squared; SRMR $=$ standardized root mean square residual; $\mathrm{TLI}=$ Tucker-Lewis Index; $\mathrm{CFI}=$ Comparative Fit Index; RMSEA = root mean squared error of approximation; $\mathrm{Cl}=$ confidence interval; $\mathrm{CFA}=$ confirmatory factor analysis; SEM = structural equation modeling; SEM-model: association between basic psychological needs satisfaction and different types of controlled and autonomous motivation and amotivation.

B-S $p=$ Bollen-Stine bootstrap level of significance (2000) samples

\section{Confirmatory Factor Analysis}

Table 3 shows that the BRSQ measurement model (six factors, 24 items), had an acceptable fit to the data in all samples. The structural model tested including $\mathrm{BPNs}$ and motivational regulations also fit the data.

Some of the standardized parameters of the measurement model (six factors and 24 items) showed factor loadings $\geq .50$ (for more details see Figure 1). 


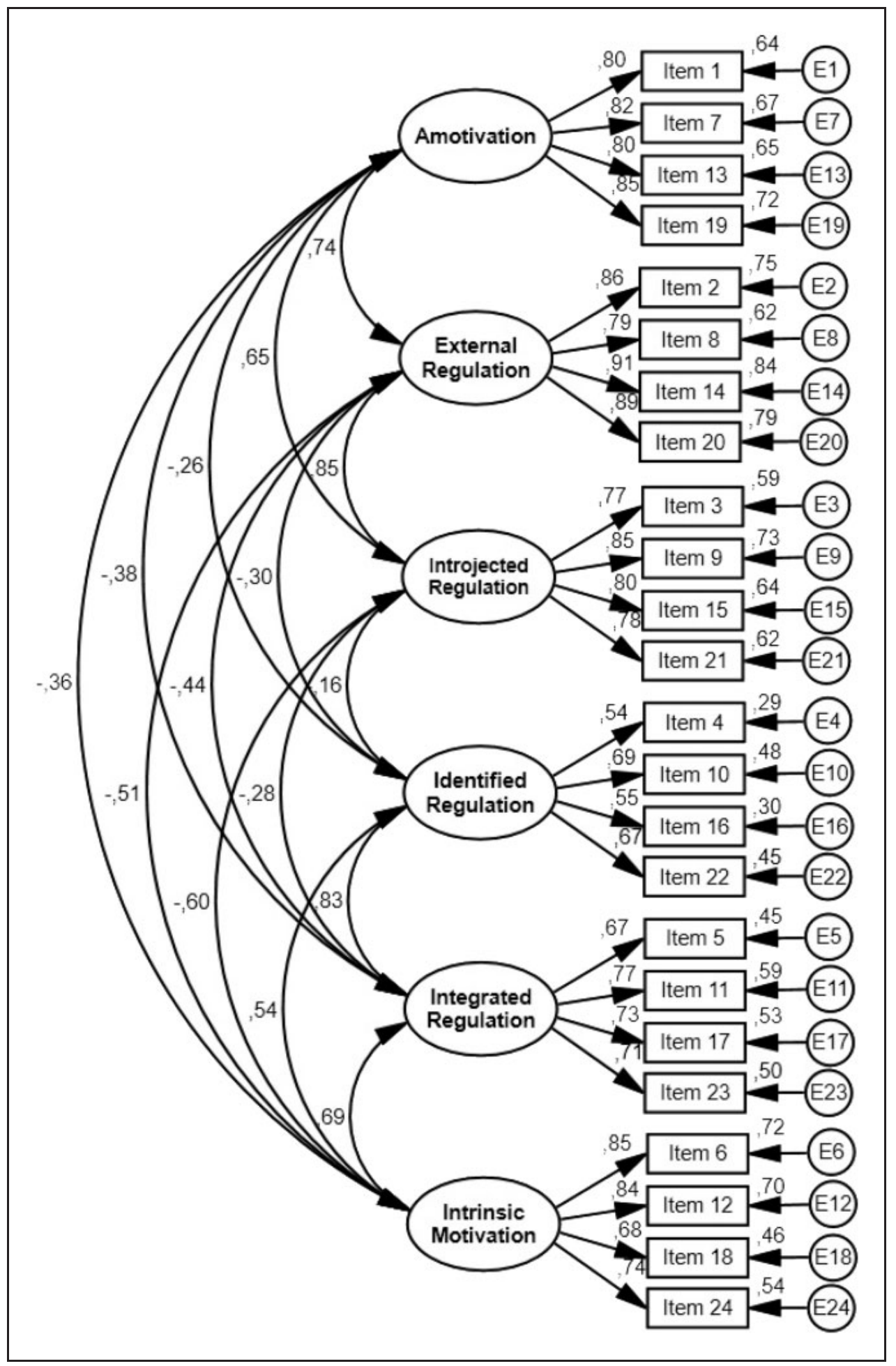

Figure I. Standardized individual parameters of BRSQ. [AQ12]

\section{Nomological Validity}

As shown in Table 4, the satisfaction of BPNs was significantly positively associated with more autonomous forms of motivation (identified, integrated, and 
Table 4. Nomological Validity Analysis.

\begin{tabular}{lcl}
\hline Path & $\beta$ & \multicolumn{1}{c}{$[90 \% \mathrm{Cl}]$} \\
\hline AUT $\rightarrow$ AM & -.27 & {$[-.330,-.218]$} \\
AUT $\rightarrow$ EXR & -.40 & {$[-.450,-.352]$} \\
AUT $\rightarrow$ IJR & -.54 & {$[-.583,-.496]$} \\
AUT $\rightarrow$ IDR & .74 & {$[.708, .763]$} \\
AUT $\rightarrow$ IGR & .92 & {$[.904, .943]$} \\
AUT $\rightarrow$ IM & .87 & {$[.837, .899]$} \\
COM $\rightarrow$ AM & -.06 & {$[-.108,-.007]$} \\
COM $\rightarrow$ EXR & -.05 & {$[-.108,-.002]$} \\
COM $\rightarrow$ IJR & -.02 & {$[-.079, .030]$} \\
COM $\rightarrow$ IDR & .14 & {$[.077, .196]$} \\
COM $\rightarrow$ IGR & .17 & {$[.105, .224]$} \\
COM $\rightarrow$ IM & .14 & {$[.081, .191]$} \\
REL $\rightarrow$ AM & -.15 & {$[-.197,-.098]$} \\
REL $\rightarrow$ EXR & -.22 & {$[-.265,-.168]$} \\
REL $\rightarrow$ IJR & -.22 & {$[-.264,-.162]$} \\
REL $\rightarrow$ IDR & .11 & {$[.060, .170]$} \\
REL $\rightarrow$ IGR & .16 & {$[.103, .217]$} \\
REL $\rightarrow$ IM & .17 & {$[.117, .226]$} \\
\hline
\end{tabular}

Note. $\quad A U T=$ autonomy; $\quad C O M=$ competence; $R E L=$ relatedness; $\quad A M=$ amotivation; $E X R=$ external regulation; IJR $=$ introjected regulation; IDR $=$ identified regulation; IGR = integrated regulation; $I M=$ intrinsic motivation.

intrinsic motivation). In contrast, the satisfaction of BPNs was significantly negatively associated with the controlled types of motivation (i.e., external and introjected regulation) as well as with amotivation. These results confirm the nomological validity of the BRSQ.

\section{Measurement Invariance}

Regarding the invariance of the measurement model (see Table 5) across-the gender and sports, results showed that, in general, the BRSQ is invariant. Furthermore, as demonstrated in Table 5, $\triangle$ CFI, $\triangle$ RMSEA, and $\triangle$ SRMR were acceptable according to F. Chen's (2007) recommendations for measurement invariance. Despite measurement invariance, in our results, it is possible to observe that residual invariance score calculated by $\triangle \mathrm{CFI}$ in all models was $>.01$ (F. Chen, 2007; Cheung \& Rensvold, 2002). 
Table 5. Goodness-of-Fit Indexes of Measurement Invariance Across Gender and Different Sports.

\begin{tabular}{|c|c|c|c|c|c|c|c|c|c|c|c|}
\hline Models & $\chi^{2}$ & $d f$ & $\Delta \chi^{2}$ & $\Delta d f$ & $p$ & $\mathrm{CFI}$ & $\Delta \mathrm{CFI}$ & SRMR & $\triangle S R M R$ & RMSEA & $\triangle \mathrm{RMSEA}$ \\
\hline \multicolumn{12}{|c|}{ Male-female } \\
\hline $\mathrm{Cl}$ & $3,803.726$ & 474 & - & - & - & .903 & - & .056 & - & .076 & - \\
\hline MI & $3,850 \cdot 136$ & 492 & 46.410 & 18 & $<.001$ & .901 & .002 & .056 & .000 & .072 & .004 \\
\hline SI & $3,919.047$ & 513 & $|15.32|$ & 39 & $<.001$ & .900 & .003 & .052 & .004 & .070 & .006 \\
\hline RI & $4,004.923$ & 537 & 201.198 & 63 & $<.001$ & .888 & .015 & .049 & .007 & .068 & .008 \\
\hline \multicolumn{12}{|c|}{ Football-swimming } \\
\hline $\mathrm{Cl}$ & $3,449.657$ & 474 & - & - & - & .921 & - & .067 & - & .072 & - \\
\hline MI & $3,575.926$ & 492 & 126.268 & 18 & $<.001$ & .916 & .005 & .067 & .000 & .071 & .001 \\
\hline SI & $3,912.303$ & 513 & 462.645 & 39 & $<.001$ & .914 & .007 & .062 & .005 & .067 & .005 \\
\hline RI & $4,123.903$ & 537 & 674.245 & 63 & $<.001$ & .902 & .020 & .058 & .009 & .062 & .010 \\
\hline \multicolumn{12}{|c|}{ Football-basketball } \\
\hline $\mathrm{Cl}$ & $2,342.393$ & 474 & - & - & - & .904 & - & .071 & - & .076 & - \\
\hline MI & $2,484.337$ & 492 & 141.944 & 18 & $<.001$ & .901 & .003 & .070 & .001 & .074 & .002 \\
\hline SI & $2,687.697$ & 513 & 345.304 & 39 & $<.001$ & .897 & .007 & .066 & .005 & .071 & .005 \\
\hline RI & $2,999.843$ & 537 & 657.450 & 63 & $<.001$ & .885 & .019 & .063 & .008 & .067 & .009 \\
\hline \multicolumn{12}{|c|}{ Football-parasport } \\
\hline $\mathrm{Cl}$ & I,877.809 & 474 & - & - & - & 911 & - & .078 & - & .078 & - \\
\hline MI & $|, 9| 9.38 \mid$ & 492 & 41.572 & 18 & .001 & .904 & .007 & .076 & .002 & .078 & .000 \\
\hline SI & $2,004.817$ & 513 & 127.008 & 39 & $<.001$ & .902 & .009 & .074 & .007 & .082 & .004 \\
\hline RI & $2,139.896$ & 537 & 262.087 & 63 & $<.001$ & .896 & .015 & .071 & .007 & .069 & .009 \\
\hline \multicolumn{12}{|c|}{ Swimming-parasport } \\
\hline $\mathrm{Cl}$ & $3,222.412$ & 474 & - & - & - & .913 & - & .069 & - & .071 & - \\
\hline MI & $3,366.481$ & 492 & 144.069 & 18 & $<.001$ & .906 & .007 & .065 & .004 & .069 & .002 \\
\hline SI & $3,600.421$ & 513 & 378.008 & 39 & $<.001$ & .904 & .009 & .061 & .008 & .067 & .004 \\
\hline RI & $3,774.821$ & 537 & 552.409 & 63 & $<.001$ & .896 & .017 & .059 & .010 & .063 & .008 \\
\hline \multicolumn{12}{|c|}{ Swimming-basketball } \\
\hline $\mathrm{Cl}$ & $2,757.677$ & 474 & - & - & - & .921 & - & .057 & - & .061 & - \\
\hline MI & $2,813.528$ & 492 & 55.851 & 18 & $<.001$ & .919 & .002 & .055 & .002 & .058 & .003 \\
\hline SI & $2,993.117$ & 513 & 235.440 & 39 & $<.001$ & .914 & .007 & .051 & .006 & .054 & .007 \\
\hline RI & $3,159.836$ & 537 & 402.158 & 63 & $<.001$ & .901 & .020 & .047 & .010 & .051 & .010 \\
\hline \multicolumn{12}{|c|}{ Basketball-parasport } \\
\hline $\mathrm{Cl}$ & I,648.763 & 474 & - & - & - & .906 & - & .072 & - & .065 & - \\
\hline MI & I,72।.99| & 492 & 73.228 & 18 & $<.001$ & .901 & .005 & .072 & .000 & .065 & .000 \\
\hline SI & I,85I.967 & 513 & 203.204 & 39 & $<.001$ & .900 & .006 & .070 & .002 & .059 & .006 \\
\hline RI & $2,076.091$ & 537 & 427.328 & 63 & $<.001$ & .892 & .013 & .066 & .006 & .057 & .008 \\
\hline
\end{tabular}

Note. $\chi^{2}=$ chi-squared; $d f=$ degrees of freedom; $\Delta \chi^{2}=$ differences in the value of chi-squared; $\Delta d f=$ differences in the degrees of freedom; $C F I=$ Comparative Fit Index; $\Delta C F I=$ differences in the value of the Comparative Fit Index; $\mathrm{Cl}=$ configural invariance; $\mathrm{MI}=$ measurement invariance; $\mathrm{SI}=$ scale invariance; $\mathrm{RI}=$ residual invariance. 


\section{Discussion}

The main objective of this study was to test the invariance of the BRSQ between the genders and among four different sport types. In addition, we found nomological validity between the satisfaction of BPNs and behavioral regulation of motivation. Results showed that the model suited the data in each of the groups under analysis and so was invariant across the-gender and the four different sports analyzed. Likewise, nomological validity was achieved, as the satisfaction of BPNs was significantly positively associated with autonomous forms of motivation and significantly negatively associated with the more controlled forms of motivation.

\section{Factorial Validity of the BRSQ in Confirmatory Factor Analysis}

This study revealed that autonomous forms of motivation were more valued by these athletes than other motivation types or amotivation. These results are in line with other studies (Lonsdale et al., 2008; Monteiro et al., 2018; Stenling et al., 2018; Villadrich et al., 2011,). Similarly, all factors show adjusted internal consistency with the values of composite reliability higher than .70 (Hair et al., 2014). Several studies have shown similar values, including those conducted in such other countries as Spain (Villadrich et al., 2011), Portugal (Monteiro et al., 2018), Sweden (Stenling et al., 2018), and others (Villadrich et al., 2013). In addition, all the factors presented adequate values of convergent validity $(\mathrm{AVE}>.50)$, indicating that the items were strongly associated with their respective factors. The only exception was the identified regulation $(\mathrm{AVE}=.38)$. However, all items presented a factorial weight $\geq .54$, and, according to Hair et al. (2014), if all factorial weights are significant and greater than .50 , then we can assume that the factors have good convergent validity. It is important to mention that problems of convergent validity in this factor have been identified in other studies (Monteiro et al., 2018; Moreno-Murcia, Marzo, Martínez-Galindo, \& Conte, 2011; Villadrich et al., 2011).

Regarding discriminant validity, our study revealed some problems involving external, introjected, identified, and integrated regulations, as the square of the correlations between them was below the AVE value in both factors (Hair et al., 2014). Several studies analyzing the psychometric properties of BRSQ reached similar results (Lonsdale et al., 2008; Monteiro et al., 2018, Moreno-Murcia et al., 2011; Villadrich et al., 2011). Thus, these constructs do not appear to be empirically distinguishable. However, theoretically, these constructs are described as quite different (Deci \& Ryan, 2008). This challenge to theory may be explained in part by the structure of the correlation patterns between the different types of motivation. Specifically, motivational regulations closer to each other through the continuum were positively correlated, while those that are further from one another conceptually were correlated less positively or even negatively (Ryan \& Connell, 1989). This evidence was recently demonstrated by Howard et al. (2017) in 486 samples under analysis. 
It is important to shed light on the existent differences among the various motivational regulations. External regulation is the most controlled state within extrinsic motivation; in it, participant behavior satisfies external contingencies (e.g., "because I feel pressure from other people to play"). As stated by Deci and Ryan (2000), introjected regulation is a more autonomous state, compared with external regulation, as, in this motivation, participant behavior is said to avoid internal punishments related to feelings of guilt and anxiety (e.g., "because I would feel guilty if I quit"). Identified regulation is characterized by participant behavior that satisfies what is personally important, even if not totally liked (e.g., "because the benefits of sport are important to me"). This regulation is theoretically distinguished from integrated regulation (Deci \& Ryan, 2000) in which the participant integrates activity into his daily routine that gels with a sense of self (e.g., "because what I do in sport is an expression of who I am").

With respect to all models tested, our study's results show a satisfactory fit to the data for all participant groups under analysis (Byrne, 2010; Hair et al., 2014; Marsh et al., 2004). These results are in line with other studies that have also analyzed the psychometric properties of the BRSQ (e.g., Hancox et al., 2015; Lonsdale et al., 2008; Monteiro et al., 2018; Stenling et al., 2018; Villadrich et al., 2011, 2013). According to these data, the BRSQ is a valid measurement tool for assessing motivational regulations associated with the motivational continuum of SDT (Deci \& Ryan, 2000) in a sport context.

\section{Nomological Validity}

The structural model fit the data regarding nomological validity between the BPNs and the different forms of motivation regulation. These results respect the cut-off values adopted by several authors (Byrne, 2010; Hair et al., 2014; Marsh et al., 2004). Specifically, the results revealed a significant positive association between the BPN's satisfaction and the more autonomous forms of motivation and a significantly negative association with the more controlled forms of motivation and amotivation. The only nonsignificant association was between competence satisfaction and introjected regulation $(\beta=-.02$, CI $[-0.07, .030])$. Nevertheless, these results corroborate the SDT framework (Deci \& Ryan, 2000), which reports that athletes' feelings of BPN satisfaction are associated with more autonomous forms of motivation. Several empirical studies have demonstrated this association (e.g., Sarrazin et al., 2002).

In this study, autonomy satisfaction presented the greatest association with more autonomous forms of motivation, followed by competence and lastly by relatedness. These findings are in line with the study by Álvarez et al. (2012) in which 370 Spanish football players were analyzed. This pattern of results supports the SDT principles outlined by Ryan and Deci (2000) who highlighted that autonomy satisfaction is the most important of the three BPNs for developing more autonomous forms of motivation. 


\section{Measurement Invariance}

Our study's results support measurement invariance of the BRSQ. Although Byrne (2010) recommends a minimum of 5:1 (five subjects by parameter to be estimated) participants for data analysis, parasport portrays a quite specific set of characteristics, and has a much lower total number of participants in comparison with general sports practice, making these participants difficult to reach and recruit. This study, however, presents a broader sample than previously published. Costa et al. (2017) validated a scale that evaluates the six types of behavioral regulation in an exercise context with a sample of 118 individuals with schizophrenia, and Banack, Sabiston, and Bloom (2011) studied coaches' support for autonomy, BPNs, and intrinsic motivation in 130 parasport athletes.

In our study, we met all of the psychometric research recommendations from experts in the field (Byrne, 2010; F. Chen, 2007; Cheung \& Rensvold, 2002), except the ones regarding residual invariance. Specifically, our results show that the same number of factors is present in this data set, independent of such participant characteristics as sport group membership (configural invariance), and all factorial weights are invariant across both the gender and sports. This means that the instrument's test items show the same importance for the factors, regardless of their characteristics (metric invariance), and that the intercepts of the items are equivalent across participants differing in both the-gender and sports (scalar invariance). As claimed by Sass (2011), scalar invariance confirmation signifies that the measurement model is suited for comparing distinct groups. Only residual invariance was not reached. However, as mentioned by Byrne (2010) and Cheung and Rensvold (2002), this criterion is considered to be optional, as it is very difficult to achieve, especially in the field of social sciences. Moreover, $\triangle$ RMSEA and $\triangle$ SRMR were acceptable according to F. Chen's (2007) criterion. Therefore, from a-practical-viewpoint, one could argue that the BRSQ possesses measurement invariance. The results of the gender invariance analysis seem to be in line with SDT constructs (Deci \& Ryan, 2000, 2008). This assumption has also been highlighted in other empirical studies conducted with the BRSQ (e.g., Lonsdale et al., 2008; Villadrich et al., 2013) and in other measurements (Hancox et al., 2015). This study also demonstrated that the BRSQ is invariant across different types of sports (i.e., football, basketball, swimming, and parasport).

Our findings help broaden knowledge about human motivation and highlight once more the suitability of this model to assess motivation in several sports. This is particularly interesting since this scale is invariant across different types of sports, including parasport, which is very specific and has received little attention regarding motivational regulations (Banack et al., 2011). According to these results and associated literature, SDT constructs are universal, regardless of the context in which they are analyzed. Likewise, they support empirically one of the most popular theoretical models for understanding cognitive, behavioral, and emotional outcomes in athletes. 


\section{Study Limitations}

Among this study's limitations is that its research design is cross-sectional, leaving a need for future studies to analyze BRSQ invariance longitudinally in order to better understand causal relationships between these variables. Second, the results of this study allow comparisons between the genders but only among participants of these particular analyzed sports. Thus, in order to broaden scientific knowledge in this area, further replications are needed with regard to participant groups comprised of participants in other sports and participant characteristics (e.g., different age groups within sports practiced, years of practice, cultures, countries, etc.).

\section{Conclusions}

In summary, this of of shows that the BRSQ can be used to evaluate motivational regulations in different sports contexts and with athletes of different characteristics. Although some weaknesses were evident in the Portuguese version of the BRSQ, this scale demonstrated construct validity (factorial, convergent, and discriminant), nomological validity, and composite reliability, and this measurement model also revealed invariance between the genders and among four different sports (football, basketball, swimming, and parasport). Motivation is one of the most important variables for continuous sport participation and acts as determinant of persistence over time (Pelletier, Fortier, Vallerand, \& Brière, 2001). Our findings provide coaches with an invariant instrument for assessing motivation; but, as complete psychometric analysis of the BRSQ can not be summarized in one study, we have recommended further specific research.

\section{Declaration of Conflicting Interests}

The author(s) declared no potential conflicts of interest with respect to the research, authorship, and/or publication of this article.

\section{Funding}

The author(s) received no financial support for the research, authorship, and/or publication of this article.

\section{ORCID iD}

Diogo Monteiro (D) http://orcid.org/0000-0002-7179-6814

Luis Cid (1) http://orcid.org/0000-0001-8156-3291

\section{References}

Álvarez, M., Balaguer, I., Castillo, I., \& Duda, J. (2012). The coach-created motivational climate, young athletes' well-being, and intentions to continue participation. Journal of Clinical Sport Psychology, 6(2), 166-179. doi:10.1123/jcsp.6.2.166 
Assor, A., Vansteenkiste, M., \& Kaplan, A. (2009). Identified versus introjected approach and introjected avoidance motivations in school and in sports: The limited benefits of self-worth strivings. Journal of Educational Psychology, 101, 482-497. doi:10.1037/ a0014236

Banack, H., Sabiston, C., \& Bloom, G. (2011). Coach autonomy support, basic need satisfaction, and intrinsic motivation of paralympic athletes. Research Quarterly for Sport and Exercise, 82(4), 722-730. doi:10.1080/027011367.2011.10599809

Byrne, B. (2010). Structural equation modelling with AMOS. Basic concepts, applications, and programming (2nd ed.). New York, NY: Taylor and Francis Group, LLC.

Chan, D., Hagger, M., \& Spray, C. (2011). Treatment motivation for rehabilitation after a sport injury: Application of the trans-contextual model. Psychology of Sport and Exercise, 12(1), 83-92. doi:10.1016/j.psychsport.2010.08.005

Chen, F. (2007). Sensitivity of goodness of fit indexes to lack of measurement invariance. Structural Equation Modeling, 14(3), 464-504.

Chen, B., Vansteenkiste, M., Beyers, W., Boone, L., Deci, E., ... Verstuyf, J. (2015). Basic psychological need satisfaction, need frustration, and need strength across four cultures. Motivation and Emotion, 39(2), 216-236. doi:10.1007/s11031-014-9450-1

Cheung, G., \& Rensvold, R. (2002). Evaluating goodness-of-fit indexes for testing measurement invariance. Structural Equation Modeling, 9(2), 233-255. doi:10.1207/ S15328007SEM0902_5

Clancy, R., Herring, M., \& Campbell, M. (2017). Motivation measures in sport: A critical review and bibliometric analysis. Frontiers in Psychology, 8, 348. doi:10.3389/ fpsyg.2017.00348

Costa, R., Probst, M., Bastos, T., Vilhena, E., Seabra, A., \& Corredeira, R. (2017). Behavioural regulation in Exercise Questionnaire in people with schizophrenia: Construct validity of the Portuguese versions. Disability and Rehabilitation, 22, 1-8. doi:10.1080/09638288.2017.134227

Deci, E., \& Ryan, R. (2000). The "what" and "why" of goal pursuits: Human needs and the self-determination of behavior. Psychological Inquiry, 11(4), 227-268. doi:10.1207/ S15327965PLI1104_01

Deci, E., \& Ryan, R. (2008). Self-determination theory: A macro theory of human motivation, development, and health. Canadian Psychology, 49(3), 182-185. doi:10.1037/ a0012801

Fornell, C., \& Larcker, D. (1981). Evaluating structural equation models with unobservable variables and measurement error. Journal of Marketing Research, 18(1), 39-50. doi: $10.2307 / 3151312$

Hair, J., Black, W., Babin, B., \& Anderson, R. (2014). Multivariate data analysis. (7th ed.). Upper Saddle River, NJ: Prentice Hall.

Hancox, J., Quested, E., Villadrich, C., \& Duda, J. (2015). Examination of the internal structure of the behavioural regulation in sport questionnaire among dancers. International Journal of Sport and Exercise Psychology, 13, 382-397. doi:10.1080/ 1612197X.2014.999347

Howard, J., Gagné, M., \& Bureau, J. (2017). Testing a continuum structure of selfdetermined motivation: A meta-analysis. Psychological Bulletin, 143, 1346-1377. doi:10.1037/bul0000125 
Jõseaar, H., Hein, V., \& Hagger, M. (2012). Youth athlete's perception of autonomy support from the coach, peer motivational climate and intrinsic motivation in sport setting: One-year effects. Psychology of Sport and Exercise, 12, 257-262. doi:10.1016/ j.psychsport.2011.12.001

Jowett, S., Adie, J., Bartholomew, K., Yang, S., Gustafsson, H., \& López-Jiménez, H. (2017). Motivational processes in the coach-athlete relationship: A multi-cultural self-determination approach. Psychology of Sport and Exercise, 32, 143-152. doi:10.1016/j.psychsport.2017.06.004 [AQ4]

Keegan, R., Harwood, C., Spray, C., \& Lavallee, D. (2014). A qualitative investigation of the motivational climate in elite sport. Psychology of Sport and Exercise, 15, 97-107. doi:10.1016/j.psychsport.2013.10.006 [AQ5]

Liu, L., Li, C., \& Zhu, D. (2012). A new approach to testing nomological validity and its application to a second-order measurement model of trust. Journal of the Association for Information Systems, 13(12), 950-975.

Lonsdale, C., Hodge, K., \& Rose, E. (2008). The Behavioral Regulation in Sport Questionnaire (BRSQ): Instrument development and initial validity evidence. Journal of Sport and Exercise Psychology, 30(3), 323-355. doi:10.1123/jsep.30.3.323

Marsh, H., Hau, K., \& Wen, Z. (2004). In search of golden rules: Comment on hypothesis testing approaches to setting cutoff values for fit indexes and dangers in overgeneralizing $\mathrm{Hu}$ and Bentler's (1999) findings. Structural Equation Modeling, 11(3), 320-341. doi:10.1207/s15328007sem1103_2

Monteiro, D., Marinho, D., Moutão, J., Couto, N., Antunes, R., \& Cid, L. (2016). Adaptation and validation of the Basic Psychological Needs Exercise Scale to the sport domain and invariance across soccer and swimming. Motricidade, 12(4), 51-61. doi:10.6063/motricidade.9372

Monteiro, D., Moutão, J., \& Cid, L. (2018). Validation of the Behavioral Regulation Sport Questionnaire in Portuguese athletes. Revista de Psicologia del Deporte, 27, 145-150.

Moreno-Murcia, J., Marzo, J., Martínez-Galindo, C., \& Conte, L. (2011). Validación de la Escala de "Satisfacción de las Necesidades Psicológicas Básicas" y del Cuestionario de la "Regulación Conductual en el Deporte" al contexto español. Revista Internacional de Ciencias del Deporte, 7(26), 355-369. doi:10.5232/ricyde2011.02602 [AQ6]

Nevitt, J., \& Hancock, G. (2001). Performance of bootstrapping approaches to model test statistics and parameter standard error estimation in structural equation modeling. Structural Equation Modeling, 8(3), 353-377. doi:10.1207/S15328007SEM0803_2

Pelletier, L., Fortier, M., Vallerand, R., \& Brière, N. (2001). Association among perceived autonomy support, forms of self-regulation, and persistence: A prospective study. Motivation and Emotion, 25(4), 279-306. doi:10.1023/A:1014805132406

Pelletier, L., Fortier, M., Vallerand, R., Tuson, M., Briére, M., \& Blais, R. (1995). Toward a new measure of intrinsic motivation, extrinsic motivation, and amotivation in sports: The Sport Motivation Scale (SMS). Journal of Sport and Exercise Psychology, 17(1), 35-53. doi:10.1123/jsep.17.1.35

Pelletier, L., Rocchi, A., Vallerand, R., Deci, E., \& Ryan, R. (2013). Validation of the revised Sport Motivation Scale (SMS-II). Psychology of Sport and Exercise, 14(3), 329-341. doi:10.1016/j.psychsport.2012.12.002 
Pelletier, L., \& Sarrazin, P. (2007). Measurement issues in self-determination theory and sport. In M. Hagger \& N. Chatzisarantis (Eds.), Intrinsic motivation and self-determination in exercise and sport [AQ7](pp. 143-152). Champaign, IL: Human Kinetics.

Ryan, R., \& Deci, E. (2000). Self-determination theory and the facilitation of intrinsic motivation, social development, and well-being. The American Psychologist, 55, 68-78. doi:10.1037110003-066X.55.1.68

Ryan, R., \& Deci, E. (2017). Self-determination theory: Basic psychological needs in motivation, development and wellness. New York, NY: The Guilford Press.

Ryan, R., \& Connell, J. (1989). Perceived locus of causality and internalization: Examining reasons for acting in two domains. Journal of Personality and Social Psychology, 57(5), 749-761. doi:10.1037/0022.3514.57.5.749

Sarrazin, P., Vallerand, R., Guillet, E., Pelletier, L., \& Cury, F. (2002). Motivation and dropout in female handballers: A 21-month prospective study. European Journal of Social Psychology, 32, 395-418. doi:10.1002/ejsp.98

Sass, D. (2011). Testing measurement invariance and comparing latent factor means within a confirmatory factor analysis framework. Journal of Psychoeducational Assessment, 29, 347-363. doi:10.1177/0734282911406661

Stenling, A., Ivarsson, A., Lindwall, M., \& Gucciardi, D. F. (2018). Exploring longitudinal measurement invariance and the continuum hypothesis in the Swedish version of the Behavioral Regulation in Sport Questionnaire (BRSQ): An exploratory structural equation modeling approach. Psychology of Sport and Exercise, 36, 187-196. doi:10.1016/j.psychsport.2018.03.002

Tsitskari, E., Vernadakis, N., Foridou, A., \& Bebetsos, E. (2015). Assessing adolescents. Sport participation motives: Psychometric evaluation of BRSQ. Motricidade, 11, 64-77. doi:10.6063/motricidade.3194

Villadrich, C., Appleton, P., Quested, E., Duda, J., Alcaraz, S., ... Ntoumanis, N. (2013). Measurement invariance of the Behavioural Regulation in Sport Questionnaire when completed by young athletes across five European countries. International Journal of Sport and Exercise Psychology, 11, 384-394. doi:10.1080/ 1612197X.2013.830434

Villadrich, C., Torregrosa, M., \& Cruz, J. (2011). Calidad psicométrica de la adaptación española del Cuestionario de Regulación Conductual en el Deporte. Psicothema, 23, 786-794. doi:10.1080/1612197X.2013.830434 [AQ8]

Vlachopoulos, S., \& Michailidou, S. (2006). Development and initial validation of a measure of autonomy, competence, and relatedness in exercise: The basic psychological needs in Exercise Scale. Measurement in Physical Education and Exercise Science, 10(3), 179-201. doi:10.1207/s15327841mpee1003_4 [AQ9]

\section{Author Biographies \\ Diogo Monteiro, II [AQ11]}

\section{Diogo S. Teixeira, 1}


Anabela Vitorino, [I

João Moutão,

Filipe Rodrigues, [I

Sérgio Machado, II

Luís Cid, II 